www.jmscr.igmpublication.org

Impact Factor 5.244

Index Copernicus Value: 83.27

ISSN (e)-2347-176x ISSN (p) 2455-0450

crossref DOI: _http://dx.doi.org/10.18535/jmscr/v4i8.61

\title{
Non-Pharmacological Treatment for Non Alcoholic Fatty Liver Disease- A Review
}

\author{
Authors \\ Tamizh Paavai Tha ${ }^{1}$,T.A.Naufal Rizwan ${ }^{* 2}$ \\ ${ }^{1}$ Bachelor of Dental Surgery, Saveetha Dental College and Hospital, Chennai, Tamilnadu, India \\ ${ }^{2}$ Department of General Medicine, Saveetha Medical College and Hospital, Chennai, Tamilnadu, India \\ *Corresponding Author \\ T.A.Naufal Rizwan \\ Department Of General Medicine \\ Saveetha Medical college and Hospital, Chennai, Tamilnadu, India
}

\begin{abstract}
Non alcoholic fatty liver disease is the most common liver disease worldwide. It is defined as an accumulation of lipids in the hepatocytes exceeding 5\% of the liver weight in the absence of excessive ethanol intake and without other causes of liver disease. Although the specific etiology is unknown, obesity related inflammation status, insulin resistance and also genetic, dietary and lifestyle changes are found to play a key role. The prevalence of NAFLD in the Asian countries is found to be between 15\%-20\%.

KEY WORDS: Non alcoholic, fatty liver, non pharmacological, diet.
\end{abstract}

\section{INTRODUCTION}

Non-alcoholic fatty liver disease (NAFLD) is a spectrum of liver disease ranging from steatosis to cirrhosis in an individual who does not consume alcohol in significant amounts ${ }^{[1]}$. Its management is of utmost importance as it acts as a risk factor for development of hepatocellular carcinoma ${ }^{[2]}$. It is closely linked with metabolic syndrome and its component parts including obesity, type II diabetes mellitus and dyslipidemia ${ }^{[3]}$. NAFLD was relatively unknown prior to the early 1980s, but is fast becoming the most common chronic liver disease worldwide, with an estimated prevalence of $20 \%-30 \%$ in Western countries ${ }^{[4]}$. This increase in cases of NAFLD is strongly linked to the rising rate in obesity; the National Health Service (NHS) database shows the percentage population with obesity has almost doubled in the last 8 years, with now roughly a quarter of the population having a raised body mass index (BMI). Changing lifestyle is ultimately to be blamed for this, including increased access to cheap food, eating on the go and marketing of high caloric foods ${ }^{[5]}$.

\section{NON PHARAMACOLOGICAL REGIMES}

In principle, management of NAFLD also involves treating the associated comorbidity, such as obesity, diabetes and dyslipidemia. 


\section{LIFESTYLE INTERVENTION}

Several interventions which are believed to be beneficial for NAFLD patients are aerobic exercise with the intensity equal to walking 30 minutes per day or $5 \mathrm{~km}$ per day 3 times a week, calorie restriction up to $30 \mathrm{kcal} / \mathrm{kg} / \mathrm{day}$ with lower composition of saturated and trans fatty acid and simple sugar. Also sudden decrease in body weight is not recommended as it may aggravate NAFLD. NAFLD also increases the risk of cardiovascular problem through inflammation process $^{[6]}$.

A study by Bhat et al, in which 60 NAFLD patients were involved in India, showed that routine physical activity for 30 minutes a day with frequency of 5 times a week can decrease transaminase level and also improve histological appearance in 6 months evaluation ${ }^{[7]}$.

Larson-Meyer et al compared the results from computerized tomography (CT) and MRI to assess the outcome of calorie restriction and exercise on a group of 46 overweight patients. The results showed that BMI, insulin resistance, alanine aminotransferase (ALT) levels, and intrahepatic steatosis decrease in all interventional groups (ALT did not decrease in the low calorie diet

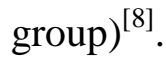

\section{DIET ONLY REGIMES}

Ryan et alpublished a paper in 2006, which was a post hoc analysis of 52 obese, insulin resistant adults who had taken part in a weight loss program. The research concludes that low carbohydrate diets are more beneficial than low fat diets at reducing ALT levels ${ }^{[9]}$.

De Luis et alreports on a 3-month intervention of hypo caloric diet (either low fat or low carbohydrate) on basic anthropological and biochemical measures in an obese population. This study reveals that even a short focused intervention (3 months) has an impact on measurable markers associated with metabolic syndrome ${ }^{[10]}$.

\section{EXERCISE ONLY REGIMES}

The benefits of physical exercise include reduction of the risk of type 2 diabetes, hypertension, dyslipidemia, metabolic syndrome, and $\mathrm{IR}^{[19]}$

Kistler et al produced the only paper in this section that used biopsy results as an outcome. The paper was a retrospective study looking at 813 biopsy results of patients with NAFLD and assessed if they were taking part in the recommended guidelines for exercise put forward by the United States Department of Health and Human Services. Participants in this trial were classified as inactive; meeting the moderate intensity guide- lines; or meeting the vigorous intensity guidelines. Thus this paper concluded that only the vigorous intensity guidelines were enough to cause significant change in liver steatosis and fibrosis ${ }^{[1]]}$.

Bae et al is one of the larger trials that reviewed this discussion. The participants were asked to fill out a questionnaire recording how much exercise they carried out on a weekly basis; regular exercise was defined as 30 minutes more than three times a week for three consecutive months. NAFLD occurrence was higher with those with a greater BMI and liver function levels were lower on average if the patient took part in regular exercise $^{[12]}$.

\section{OTHER DIETARY INTERVENTIONS}

Several population studies stated that in NAFLD patients, there was lower omega-3 consumption, higher omega- 6 consumption, and also higher amount of cholesterol and saturated fatty acid, and less consumption of some vitamins, such as: ascorbic acid, tocopherol, and fiber. Meanwhile a study using $1,000 \mathrm{mg} / \mathrm{day}$ and $2,700-\mathrm{mg} / \mathrm{day}$ omega-3 in NAFLD patients revealed that omega3 decrease ALT, improve the degree of perlemakan in ultrasound, and improve histological appearance, however the number of samples included was 42 and 23 patients ${ }^{[13]}$.

Alcohol consumption that is known as a risk factor for impairment of liver function tends to 
produce the opposite effect when consumed in small amounts. The American Association for the Study of Liver Disease (AASLD) recommend NAFLD patients to not consume alcohol in large amount, which is 4 times per day or 14 times per week for male and 3 times per day or 7 times per week for female ${ }^{[14]}$.

\section{BARIATRIC SURGERY}

Bariatric surgery has an increasing role in the management of patients with obesity and the metabolic syndrome. Restrictive procedures such as the gastric band, gastric balloon and sleeve gastrectomy decrease stomach size leading to early satiety. Malabsorptive procedures such as gastric bypass limit the absorption of food. Weight loss after bariatric surgery has beneficial effects on the components of the metabolic syndrome including improving insulin sensitivity, lipid profile as well as reducing long-term mortality ${ }^{[15][16]}$. The optimum type of bariatric surgery for the treatment of NASH is not known ${ }^{[17]}$. As there is a lack of long-term outcome data about bariatric surgery as a specific treatment for NAFLD, bariatric surgery cannot be considered as a primary treatment for $\mathrm{NASH}^{[18]}$.

\section{CONCLUSION}

Thus this review summarizes all the various non pharmacological treatment options to treat non alcoholic fatty liver disease. Lifestyle changes with weight loss and exercise along with control of underlying risk factors remains the cornerstone of the therapy.Presence of comorbidity can be a consideration in choosing treatment in NAFLD. Thus this review helps the clinician to have a better understanding regarding the benefits of the various non pharmacological treatment option for the treatment of NAFLD prior to pharmacological intervention.

\section{ACKNOWLEDGEMENT}

The materials collected to compile the article from various literature sources, journals and website database are duly acknowledged.

\section{REFERENCES}

1. Deepak NA, Estsuko H, Laurentius AL, José DS, Pei-JC, Khean-LG, et al. How common is non-alcoholic fatty liver disease in the Asia-Paci c region and are there local differences?. J Gastroenterol Hepatol 2007;22:788-93.

2. György B, Elizabeth MB, Stephen HC. Hepatocellular carcinoma in non-alcoholic fatty liver disease: an emerging menace. $\mathrm{J}$ Hepatol 2012;56:1384-91.

3. Bellentani S, Scaglioni F, Marino M, Bedogni G. Epidemiology of nonalcoholic fatty liver disease. Dig Dis. 2010;28(1):155-161.

4. Bedogni G, Miglioli L, Masutti F, Tiribelli C, Marchesini G, Bellentani S. Prevalence of and risk factors for nonalcoholic fatty liver disease: the Dionysos nutrition and liver study. Hepatology 2005;42(1):44-52.

5. ames WP. The epidemiology of obesity: the size of the problem. J Intern Med. 2008;263(4):336-352.

6. Nimer A. Nutritional recommendations for patients with non-alcoholic fatty liver diseases. World J Gastroenterol 2011;17: 3375-6.

7. Bath G, Baba CS, Pandey A, Kumari N, Choudhuri G. Life style modification improves insulin resistance and liver histology in patients with non-alcoholic fatty liver disease. World J Hepatol 2012;4:209-17.

8. Larson-Meyer DE, Newcomer BR, Heilbronn LK, et al; Pennington CALERIE Team. Effect of 6-month calorie restriction and exercise on serum and liver lipids and markers of liver function. Obesity (Silver Spring). 2008;16 (6):1355-1362.

9. Ryan MC, Abbasi F, Lamendola C, Carter S, McLaughlin TL. Serum alanine aminotransferase levels decrease further with carbohydrate than fat restriction in 
insulin-resistant adults. Diabetes Care. 2007;30(5): 1075-1080.

10. de Luis DA, Aller R, Izaola O, Gonzalez Sagrado M, Conde R. Effect of two different hypocaloric diets in transaminases and insulin resis- tance in nonalcoholic fatty liver disease and obese patients. Nutr Hosp. 2010;25(5):730-735.

11. Kistler KD, Brunt EM, Clark JM, Diehl AM, Sallis JF, Schwimmer JB; NASH CRN Research Group. Physical activity recommendations, exercise intensity, and histological severity of nonalcoholic fatty liver disease. Am $J$ Gastroenterol. 2011;106(3):460-468; quiz 469.

12. Bae JC, Suh S, Park SE, et al. Regular exercise is associated with a reduction in the risk of NAFLD and decreased liver enzymes in indi- viduals with NAFLD independent of obesity in Korean adults. PLoS One. 2012;7(10):e46819.

13. Shira ZS, Vlad R, Ran O. Nutrition and physical activity in NAFLD: an overview of the epidemiological evidence. World J Gastroenterol 2011;17:3377-89.

14. Chalasani N, Younossi Z, Joel EL, Anna MD, Elizabeth MB, Kenneth C, et al. The diagnosis and management of nonalcoholic fatty liver disease: practice guideline by the American Association for the Study of Liver Diseases, American College of Gastroenterology, and the American Gastroenterological Association. Hepatology 2012;55:2005-23.

15. Sjostrom L, Lindroos AK, Peltonen M, et al. Lifestyle, diabetes, and cardiovascular risk factors 10 years after bariatric surgery. NEJM 2004;351:2683-93.

16. Sjostrom L, Narbro K, Sjostrom CD, et al. Effects of bariatric surgery on mortality in Swedish obese subjects. NEJM 2007;357: 741-52.
17. Mathurin P, Hollebecque A, Arnalsteen L, et al. Prospective study of the long-term effects of bariatric surgery

18. Chavez-Tapia NC, Tellez-Avila FI, Barrientos-Gutierrez $\mathrm{T}$, et al. Bariatric surgery for non-alcoholic steatohepatitis in obese patients. Cochrane Database System Rev 2010:CD007340.

19. Lee IM, Shiroma EJ, Lobelo F, Puska P, Blair SN, Katzmarzyk PT, et al. Effect of physical inactivity on major noncommunicable diseases worldwide: an analysis of burden of disease and life expectancy. Lancet. 2012;380:219-229. 